\title{
Streamflow Forecasting without Models
}

\author{
Witold F. KRAJEWSKI, GANESH R. GHIMIRE, AND FELIPE QUINTERO \\ Iowa Flood Center and IIHR-Hydroscience and Engineering, The University of Iowa, Iowa City, Iowa
}

(Manuscript received 13 December 2019, in final form 22 May 2020)

\begin{abstract}
The authors explore persistence in streamflow forecasting based on the real-time streamflow observations. They use 15-min streamflow observations from the years 2002 to 2018 at 140 U.S. Geological Survey (USGS) streamflow gauges monitoring the streams and rivers throughout Iowa. The spatial scale of the basins ranges from about 7 to $37000 \mathrm{~km}^{2}$. Motivated by the need for evaluating the skill of real-time streamflow forecasting systems, the authors perform quantitative skill assessment of persistence schemes across spatial scales and lead times. They show that skill in temporal persistence forecasting has a strong dependence on basin size, and a weaker dependence on geometric properties of the river networks. Building on results from this temporal persistence, they extend the streamflow persistence forecasting to space through flow-connected river networks. The approach simply assumes that streamflow at a station in space will persist to another station which is flow connected; these are referred to as pure spatial persistence forecasts (PSPF). The authors show that skill of PSPF of streamflow is strongly dependent on the monitored versus predicted basin area ratio and lead times, and weakly related to the downstream flow distance between stations. River network topology shows some effect on the hydrograph timing and timing of the peaks, depending on the stream gauge configuration. The study shows that the skill depicted in terms of Kling-Gupta efficiency (KGE) $>0.5$ can be achieved for basin area ratio $>0.6$ and lead time up to 3 days. The authors discuss the implications of their findings for assessment and improvements of rainfall-runoff models, data assimilation schemes, and stream gauging network design.
\end{abstract}

\section{Introduction}

In this paper we demonstrate, in a systematic way, that persistence is a hard-to-beat streamflow forecasting method (Palash et al. 2018), a fact well known to operational forecasters. We limit our considerations to realtime forecasting in space and time in a river network. River networks aggregate water flow that originates from the transformation of rainfall and/or snowmelt to runoff. Additional recognition of the importance of river networks stems from the fact that many communities reside by streams and rivers and thus require streamflow forecasts on a regular basis for a number of applications ranging from flood protection to water resource management.

Our study is motivated by 10 years of experience of the Iowa Flood Center (IFC) providing operational real-time streamflow forecasts for the citizens of Iowa (Demir and Krajewski 2013; Krajewski et al. 2017).

Corresponding author: Witold F. Krajewski, witold-krajewski@ uiowa.edu
The IFC has accomplished this in a traditional way, i.e., using a statewide implementation of a distributed rainfall-runoff model. The IFC model is referred to as the hillslope-link model (HLM) and has its origins in landscape decomposition discussed by Mantilla and Gupta (2005). The HLM has been presented and its performance discussed in several prior studies, including Cunha et al. (2012), Ayalew et al. (2014a,b), ElSaadani et al. (2018), and Quintero et al. (2018, 2020). In addition, the National Weather Service, via its North Central and Central River Forecasts Centers issues "official" streamflow forecasts for a number of locations throughout the state of Iowa (e.g., Zalenski et al. 2017).

In this study, we take a step back and ask the question: how well could someone forecast streamflow without a rainfall-runoff model? What would be the skill and limitations of such forecasts? We address these questions using the approach of simple persistence applied both in space and in time. We explore a range of forecast lead times, from hours to days ahead, and characterize their skill according to several popular metrics used in 
evaluation of hydrologic models. Our study domain is the entire state of Iowa but without considering the border rivers, i.e., the Mississippi and the Missouri Rivers. Iowa has a dense drainage network of streams and rivers that feed its border rivers. The state is home to some 1000 communities located near streams and rivers and is frequented by severe storms and the resultant floods. The U.S. Geological Survey (USGS) operates and collects streamflow data in real time at some 140 stream gauges in Iowa and the IFC has deployed 250 stage-only sensors (Kruger et al. 2016; Krajewski et al. 2017).

Streamflow forecasting in space without using hydrologic models is little studied, and limited efforts have been documented in the literature. Some recent probabilistic approaches (Botter et al. 2008; Müller et al. 2014) include a physically based mechanism for hydrologic predictions in sparsely gauged basins under changing climatic conditions (Doulatyari et al. 2015; Müller and Thompson 2016; Dralle et al. 2016). However, the spatial cross correlations among multiple basin outlets have not been studied in this framework (Betterle et al. 2017). Specifically, geostatistical methods have been effectively employed to explore spatial patterns in streamflow accounting for the river network topology (e.g., Betterle et al. 2017; Castiglioni et al. 2011; Laaha et al. 2014; Skøien et al. 2006). Spatial streamflow correlation has been proven to be a better indicator in transferring the flow attributes to ungauged outlets from gauged outlets in comparison to proximity (Betterle et al. 2017). Notwithstanding the progress achieved over the last few years in spatial streamflow predictions, further efforts on exploiting the spatial and temporal persistence of streamflow in the context of streamflow forecasting is needed and this study follows in that direction. A short note on our use of the term "forecasting." We decided to use it, instead of a perhaps more general term "prediction," simply to emphasize the real time and operational aspects of the problem.

We organize this paper as follows. In section 2, we present the data used in our investigations and describe Iowa and its major river basins. In section 3 , we describe the experimental setup for our analysis and discuss the performance metrics used to characterize the skill of the persistence forecasting. Section 4 documents our findings reported as a function of spatialscale characteristics. We also discuss the connection to the river network geometry depicted in terms of width function. We end with a discussion of implications of our study for operational forecasting systems, hydrologic and hydraulic models, river basin gauging network design as well as data assimilation and artificial intelligence (AI) methods.

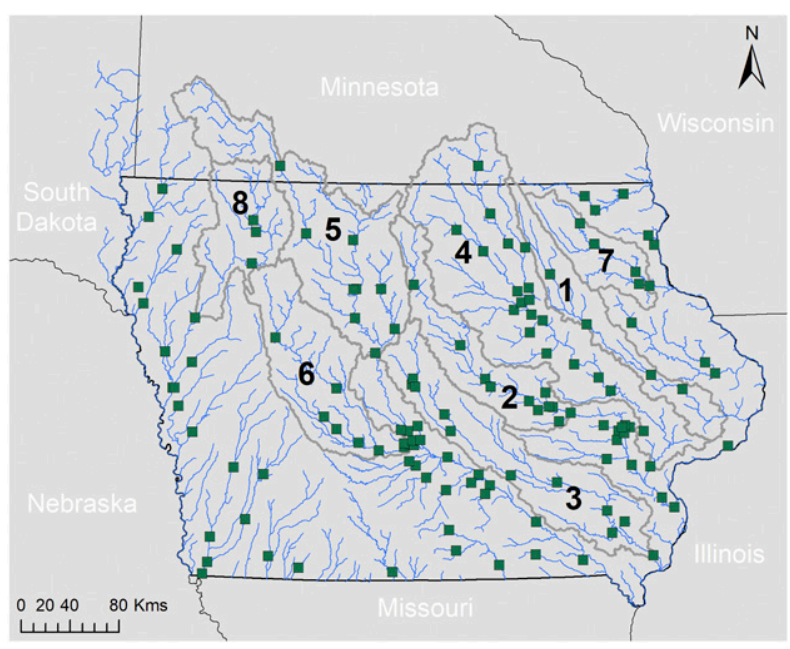

FIG. 1. USGS stream gauges over the state of Iowa used in this study. Numbered labels show the river basins with multiple gauges, thus enabling assessment of skill of persistence forecasting in space.

\section{Experimental domain and data}

We explore the forecasting skill of simple persistence in both time and space. Our domain of interest is the state of Iowa and its interior rivers (Fig. 1). Iowa is bordered by the Mississippi River on the east and the Missouri River on the west side. The interior rivers all discharge to these two large rivers with about twothirds of the state's $150000 \mathrm{~km}^{2}$ area draining to the Mississippi. Most drainage basins of those interior rivers are contained within the administrative borders of the state, but a small portion drains parts of southern Minnesota and South Dakota.

The climate of Iowa is characterized by marked seasonal variations due to its latitude and interior continental location. During the warm season, the moist air coming from the Gulf of Mexico produces a summer rainfall maximum; during the cold season, flow of dry Canadian air causes cold and dry winters. The air masses moving across the western United States throughout the year produce mild and dry weather.

The landscape is predominantly agricultural, characterized by low relief, fertile soils, high drainage density and thus numerous rivers (e.g., Prior 1991). Much of the state is covered by tile drains, thus changing the hydrologic regime of the region (e.g., Schilling et al. 2019). The combination of the characteristics of its landscape, together with significant rainfall during the summer months makes the state prone to the occurrence of floods (e.g., Villarini et al. 2011a, 2013; Mallakpour and Villarini 2015; Villarini et al. 2011b).

The U.S. Geological Survey currently operates about 140 stream gauges in the state (Fig. 1), which provide 


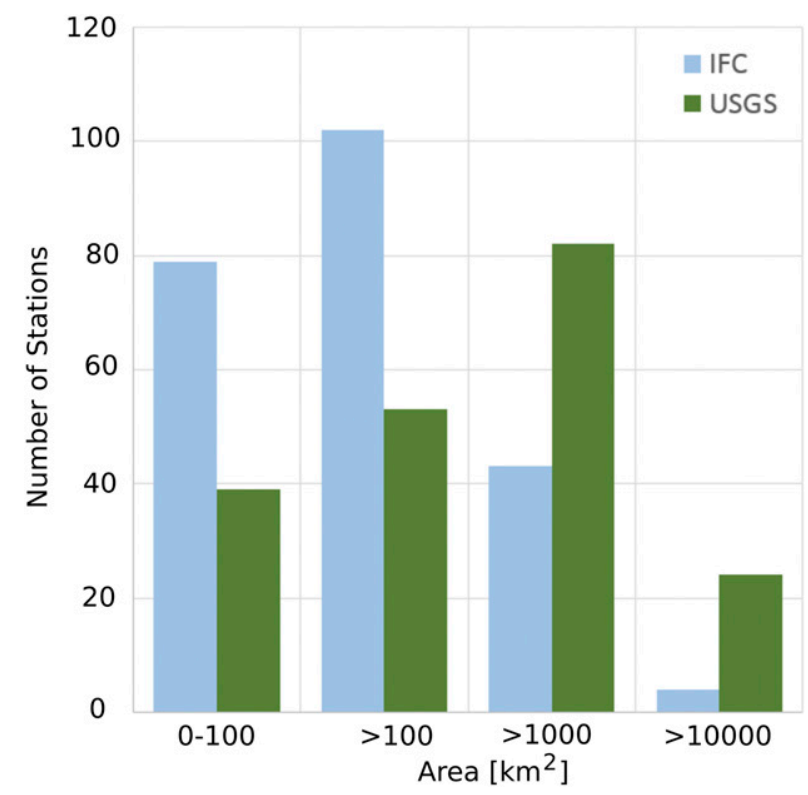

FIG. 2. Distribution of the IFC (blue) and the USGS (green) stream gauges over the state of Iowa. It is apparent that most USGS gauges monitor streamflow at larger basin scales.

15-min resolution stage data that can be converted to discharge using well-maintained and frequently updated rating curves. The USGS record of 15 -min data has only 17 years but we claim that this is sufficient to illustrate the objectives of our study. Though the Iowa Flood Center has added 250 stage-only gauges (Kruger et al. 2016), we will not use the data in this study. Figure 2 shows the basin size histogram at the outlet of these two sets of gauges. It is clear that the IFC emphasizes monitoring smaller basins than the USGS.

In addition to the discharge data, we will make use of the water flow velocity data collected by the USGS. The velocity data are synthetized into a simple powerlaw model documented by Ghimire et al. (2018). In the later part of the paper, we will refer to the model simulation results for the Iowa domain. The model, called the hillslope-link model, is briefly presented in Krajewski et al. (2017) and several other publications (e.g., Quintero et al. 2020, 2018, 2016; ElSaadani et al. 2018; Cunha et al. 2012; Ayalew et al. 2014b; Small et al. 2013). A notable point of the model's use in the operation of the IFC is that the model has not been calibrated in the classic meaning of the practice.

\section{Methods}

\section{a. Experimental design}

We investigated the streamflow forecasting performance of a simple persistence approach in time and in space. We considered a range of spatial scales $(\sim 10$ $\left.10000 \mathrm{~km}^{2}\right)$ as well as a range of the forecast lead times (from 15 min to 5 days). Let us denote locations where we would like to forecast streamflow with index $i$ and the stations which data we use to make the forecast as $j$. In the time domain, in which only index $i$ is relevant, the streamflow $Q$ forecasting equation becomes simply

$$
Q_{i}\left(i, t_{0}+\Delta t\right)=Q_{i}\left(i, t_{0}\right),
$$

where the time of issuing the forecast is $t_{0}$ and $\Delta t$ is the forecast lead time, $\Delta t=\left[0, \Delta t_{\max }\right]$. Here, we simply repeat the main findings documented in Ghimire and Krajewski (2020). These authors investigated three different persistence approaches for $\Delta t$ ranging between $15 \mathrm{~min}$ and 5 days, but here we present the results of the simplest one only, i.e., that the future will be the same as the present, as given by (1). In Fig. 3, we illustrate the result from this approach with 15-min of streamflow data from 2002 to 2018 at about 140 USGS stations. It is clear that for small-scale basins, where the streamflow variability is large and the basin response time short, the persistence forecasting quickly loses skill. For large basins, the skill persists for considerable forecast lead time.

In space, to be fully parallel to the investigation in the time domain, we first investigated scenarios where time is not involved. Here, however, the 140 USGS stream gauges must be stratified not only by basin size but also by basin membership. We only considered gauges that belong to the same basin and thus are flow connected in either downstream or upstream direction (but not both). Therefore, we excluded consideration of hydroclimatic similarity and land use or ecosystem classification (e.g., Schilling et al. 2015). For example, a basin in western Iowa is excluded from considerations for persistence forecasting in eastern Iowa.

In Fig. 1, we show the major basins in the state and in Table 1 we provide details on USGS gauges in each. Now, within a basin we can consider all potential forecasting versus evaluation scenarios. For example, consider the situation of a supposed basin with five gauges as numbered in Fig. 4. First, consider downstream direction only. Hypothetically, one could apply the persistence forecasting paradigm using data from gauge 1 to forecast streamflow at gauge 5 . The results might not be very good as gauge 1 misses the contributions from a large portion of the basin and major tributaries upstream from gauge 5. Similarly, one could evaluate the forecasting performance at gauge 5 using data from gauges 2,3 , and 4 . Or, one could evaluate the spatial persistence at gauge 3 using data from gauges 1 or 2 but 

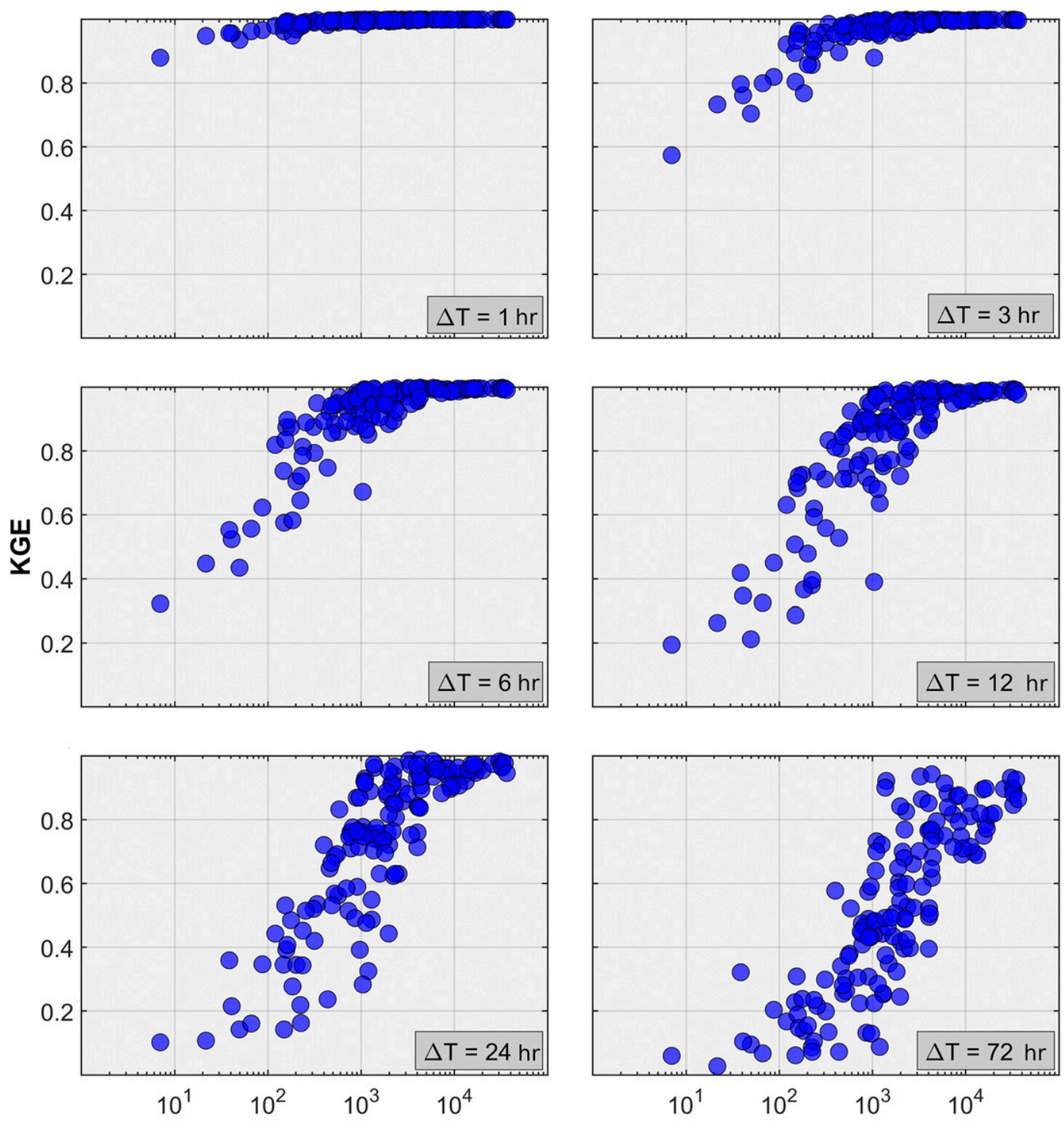

\section{Drainage Area $\left[\mathrm{km}^{2}\right]$}

FIG. 3. Variability of KGE based on simple persistence forecasting approach across basin scales for different lead times (after Ghimire and Krajewski 2020). The forecast skill in terms of KGE shows clear dependence on basin scales and forecast time horizon.

not 4 or 5 . Gauge 5 is flow connected with gauge 3 but in the upstream direction. Gauge 4 is not flow connected with gauge 3 as the connection would require downstream and upstream direction for water travel.

Similarly, if we consider the upstream direction, one could make forecast at gauge 1 using data from gauge 5 . Full analogy follows for all other pairing. In summary, for this example basin, we have seven pairs to consider in each direction; they are $(1,2),(1,3),(1,5),(2,3),(2,5)$, $(3,5)$, and $(4,5)$. These pairs of the forecast and evaluation points will allow us to evaluate persistence forecasting in space as function of spatial scale. We will refer to these forecasting scenarios as single point forecasts (SPF).

The above discussion is valid for the forecast lead time equal to zero, i.e., streamflow observed now at location $i$ is the same as the forecast at location $j$. We can extend the same construction to other lead times $\Delta t=0, \ldots$, $\Delta t_{\max }$. The forecast at location $i$ for the lead time $\Delta t$ is the same as the flow now at the stream gauge $j$. In terms of the spatial arrangement between the forecast and evaluation points, nothing changes, i.e.,

$$
Q_{i}\left(i, t_{0}+\Delta t\right)=Q_{j}\left(j, t_{0}\right) \quad \text { for } \quad \Delta t=0, \ldots, \Delta t_{\max } .
$$


TABLE 1. Basin characteristics with linear regression-based model parameters for KGE $\left(\mathrm{KGE}=\alpha+\beta A_{r}\right)$.

\begin{tabular}{|c|c|c|c|c|c|c|c|c|}
\hline ID & Basin & Area $\left(\mathrm{km}^{2}\right)$ & No. of stations & No. of stations per $\mathrm{km}^{2}$ & $\alpha$ & $\beta$ & $R^{2}$ & RMSE \\
\hline 1 & Wapsipinicon River & 6000 & 4 & 0.67 & -0.45 & 1.44 & 0.94 & 0.11 \\
\hline 2 & Iowa River & 7300 & 11 & 1.51 & -0.39 & 1.41 & 0.97 & 0.09 \\
\hline 3 & Skunk River & 11300 & 11 & 0.97 & -0.43 & 1.44 & 0.97 & 0.08 \\
\hline 4 & Cedar River & 20100 & 20 & 1.00 & -0.44 & 1.43 & 0.98 & 0.07 \\
\hline 5 & Des Moines River & 14300 & 9 & 0.63 & -0.61 & 1.60 & 0.96 & 0.10 \\
\hline 6 & Raccoon River & 9400 & 9 & 0.96 & -0.41 & 1.39 & 0.96 & 0.09 \\
\hline 7 & Turkey River & 4100 & 5 & 1.22 & -0.38 & 1.39 & 0.97 & 0.08 \\
\hline 8 & Little Sioux River & 6300 & 4 & 0.63 & -0.41 & 1.40 & 0.98 & 0.08 \\
\hline
\end{tabular}

Now, let us expand the forecasting setup. Following the same example in Fig. 4, it is clear that if one adds data from gauge 3 and gauge 4 , the forecasts at gauge 5 should improve, perhaps considerably. However, forecasting at gauge 3 does not benefit from considering data from gauge 1 and gauge 2 together. For the example basin in Fig. 4, there is only one multipoint forecast (MPF) combination possible. However, for larger basins with rich river networks and dense system of gauges, there could be several to consider. Note, that in the upstream direction there are no MPFs possible. As earlier, considering different forecast lead times do not change the spatial arrangements between the forecast and evaluation points. Mathematically,

$Q_{i}\left(i, t_{0}+\Delta t\right)=\sum_{j=1}^{n} Q_{j}\left(j, t_{0}\right)$ for $\Delta t=0, \ldots, \Delta t_{\max }$,

where $n$ is the number of stream gauges that constitute an MPF.

Next, let us add a simple travel time consideration. Since it is well established that in most places the direction of water movement is easy to predict, we can add water flow velocity and river distance information to the persistence forecasts. The simplest choice for water flow velocity is a constant value. Mathematically, for a SPF

$$
Q_{i}\left(i, t_{0}+\Delta t\right)=Q_{j}\left(j, t_{0}+\frac{d}{v}\right) \text { for } \Delta t=0, \ldots, \Delta t_{\max },
$$

where $v$ is a constant water flow velocity and $d$ is the distance along the river network between locations $i$ and $j$. Recognizing that water flow velocity is a nonlinear function of discharge and other channel parameters (e.g., Ghimire et al. 2018; Mantilla 2007; Ayalew et al. 2014a,b), we limit our consideration to the constant velocity and SPF case to keep the setup simple.

As river networks display a wide range of shapes (topologies) that may affect hydrologic response (e.g. Ayalew and Krajewski 2017; Perez et al. 2018), it is interesting to check their effect on the forecasting skill of persistence (also see Ghimire and Krajewski 2020). To accomplish this, we consider the width function of the basins defined by the existing USGS gauges. Basin width function (WF) can be interpreted as a distribution of stream segments (distances) with respect to the outlet of the basin (e.g., Rodriguez-Iturbe and Rinaldo 1997). If one assumes constant water flow velocity, the distribution of distances is equivalent to the distribution of travel times. Consider the width functions of the Cedar River at Cedar Rapids and the Iowa River at Marengo (Fig. 5). We can see that the maximum of the travel time for the Cedar River basin is located some $200 \mathrm{~km}$ away from the outlet at Cedar Rapids. For the Iowa River, the maximum is just upstream from Marengo, some $50 \mathrm{~km}$ from the outlet. Note that in Fig. 5, the travel time between the forecast point (red dot) and the evaluation point at basin outlet (green dot) is the same. In addition,

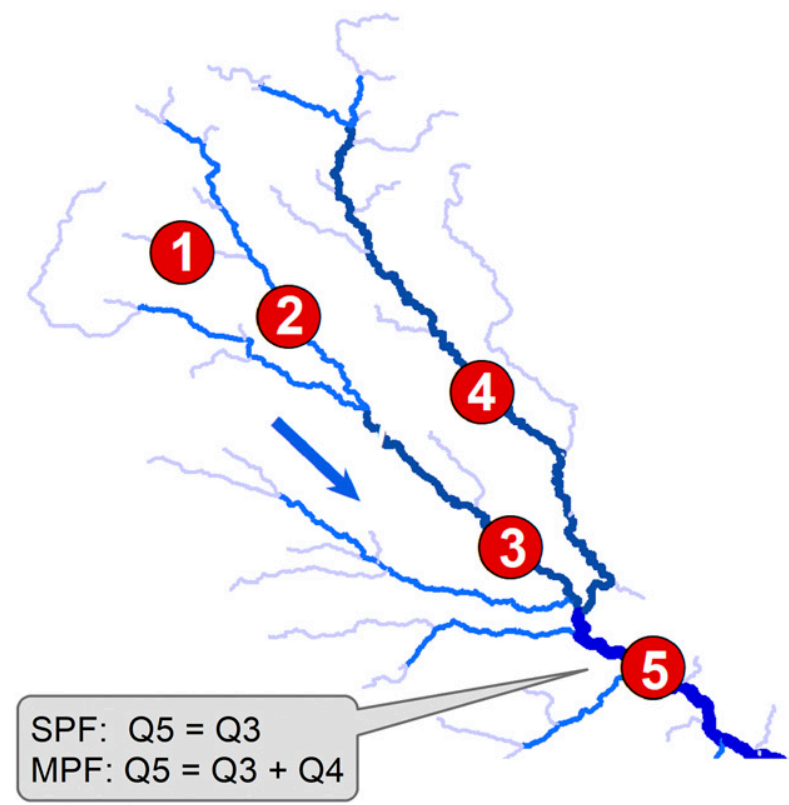

FIG. 4. Demonstration of experimental setup for the spatial persistence forecasting. The arrow shows direction for streamflow forecast in a flow connected river network. The schematic illustrates SPF and MPF. In the upstream direction, only SPF is possible. 


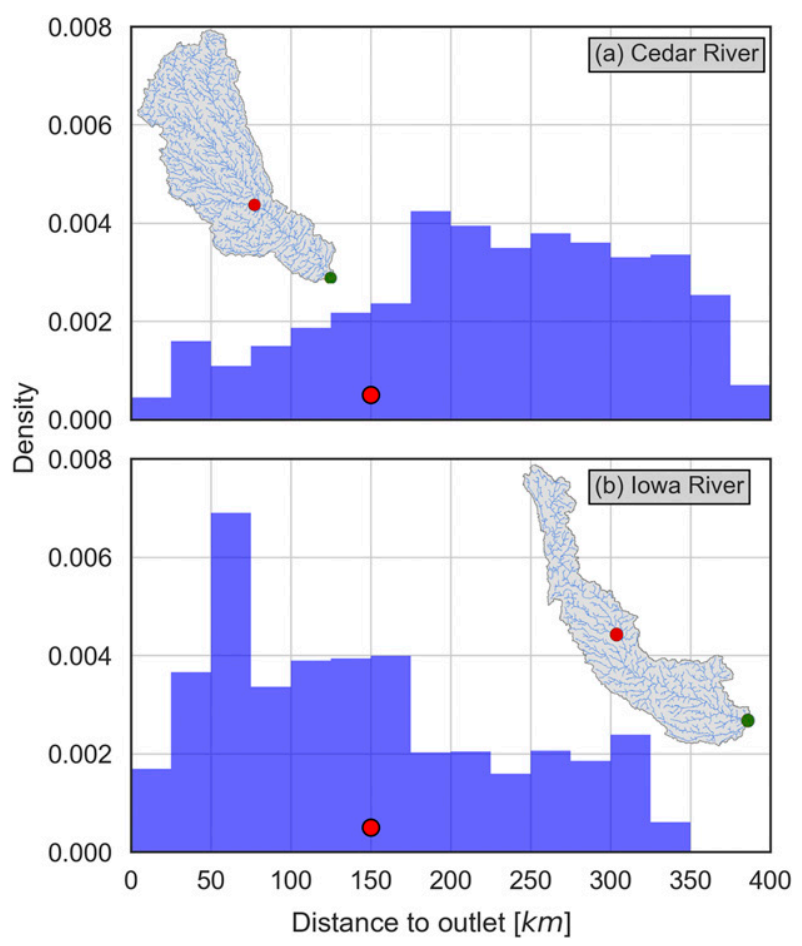

FIG. 5. Width function depicting normalized histogram (density) of distance of each link in the river network to the basin outlet. (a) Width function for the Cedar River at Cedar Rapids and (b) width function for the Iowa River at Marengo. The red dot represents the SPF with the evaluation site being the basin outlet (green dot).

the base of the width function is also similar $(\sim 350 \mathrm{~km})$. However, the forecast point of the Cedar River basin entails not only the peak of the width function, but it also monitors a larger upstream drainage area.

These differences in the shape of the basin may influence the collective performance of persistence-based forecasting, especially for the MPF scenarios. However, since considering the entire distribution is inconvenient, we examined several simple geometric descriptors of width functions (see Perez et al. 2018) such as base of the width function $D_{B}$, centroid of the width function $\bar{d}$, mass of the width function $M$, and distance to the peak of the width function $d_{W \max } . D_{B}$ represents the longest stream link distance to the outlet, $\bar{d}$ represents the first moment of area under the WF curve, $M$ essentially represents the area under the WF curve and $d_{W \max }$ corresponds to the distance from outlet to the peak of the WF. Perez et al. (2018) and Ghimire and Krajewski (2020) concluded that normalized form of $D_{B}$ explains the most variability in performance metrics. Whether the forecasting scenario is SPF or MPF, we define relationships between forecast and evaluation points in pairs. Therefore, the ratio of $D_{B}$ explains the same variability as normalized $D_{B}$, which we discuss later in detail.

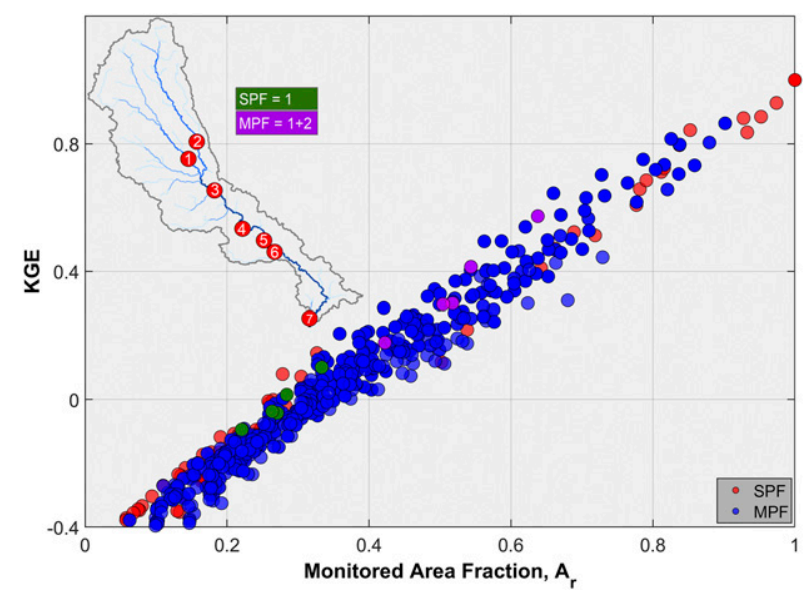

FIG. 6. Relationship of the KGE metric with monitored area fraction $A_{r}$ for the Cedar River basin for the year 2016. Every dot in this figure implicitly represents a pair of forecast and evaluation points. Red dots show SPF performance while blue dots represent MPF forecast performance. As a demonstration of improvement in performance of MPF based forecast from SPF based forecast consider the green and magenta points. The green dots are evaluation points 3-7 using SPF at forecast point 1 . The magenta dots are the same evaluation points upon addition of forecast point 2 to point 1 showing a dramatic increase in the KGE metric.

\section{b. Evaluation metrics}

We evaluated persistence derived streamflow forecasts in space and time against USGS streamflow observations at evaluation points. We computed forecast skills in terms of several statistical metrics. The major performance skill measures we report here are KlingGupta efficiency (KGE), nonparametric KGE, mean absolute error (MAE), normalized MAE (nMAE), hydrograph timing $\left(T_{H}\right)$, timing of the annual peak $\left(T_{P}\right)$, and percent peak difference (PPD). The KGE metric has three components: Pearson's correlation $r$, variance ratio $\alpha$, and mean ratio $\beta$ (see Gupta et al. 2009). The ideal value of $\mathrm{KGE}$ is equal to 1 :

$$
\mathrm{KGE}=1-\sqrt{(r-1)^{2}+(\alpha-1)^{2}+(\beta-1)^{2}},
$$

where $\alpha=\sigma_{s} / \sigma_{o}$, and $\beta=\mu_{s} / \mu_{o}, \sigma_{s}$ is the variance of forecasts, $\sigma_{o}$ is the variance of observations, $\mu_{s}$ is the mean of forecasts, and $\mu_{o}$ is the mean of observations. As an example, if the variance ratio $\alpha$ and the mean ratio $\beta$ are close to one, the KGE is dominated by the correlation coefficient $r$. The frontier of KGE for good/bad forecasts relative to the mean of the observations could be considered as -0.41 (Knoben et al. 2019). Knoben et al. (2019) showed that the interpretation of KGE metric should not be guided by our understanding of Nash-Sutcliffe efficiency (NSE) values. A modification was proposed by Pool et al. (2018) to get away with the 

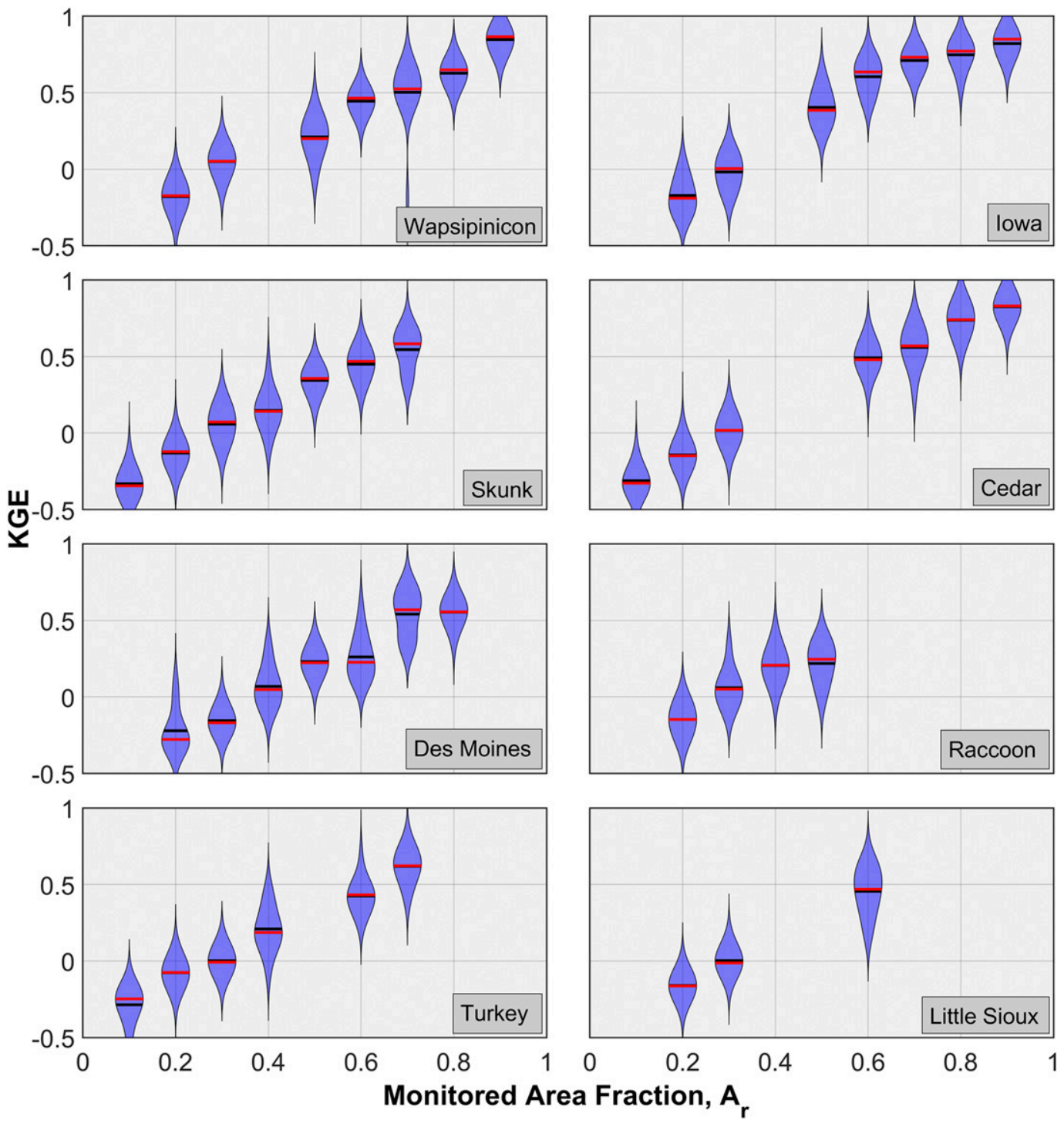

FIG. 7. Violin plots showing interannual variability of KGE metric with monitored area fraction $A_{r}$ across basins in Iowa. Each violin plot shows distribution of KGE over the period of 2002-18. The red line and black line show median and mean, respectively, of the KGE over the years.

implicit assumption of linearity of data, normality of data and the absence of outliers in the formulation of KGE by Gupta et al. (2009). It comprises nonparametric components, i.e., Spearman rank correlation and normalized flow duration curve while the mean ration (multiplicative bias) component stays the same. The modified measure is given by

$$
\mathrm{KGE}_{\mathrm{NP}}=1-\sqrt{\left(r_{s}-1\right)^{2}+\left(\alpha_{\mathrm{NP}}-1\right)^{2}+(\beta-1)^{2}},
$$

where $r_{s}$ is the Spearman rank correlation and $\alpha_{\mathrm{NP}}$ is the normalized flow duration curve. For further details, readers are referred to Pool et al. (2018).
Likewise, we report MAE for stage forecasts associated with streamflow forecasts derived using rating curves and is given by

$$
\mathrm{MAE}=\frac{1}{N} \sum\left|h_{s}-h_{o}\right|,
$$

where $h_{s}$ and $h_{o}$ are forecast and observed stage, respectively, and $N$ is the total number of time series nodes. Also, it is interesting for streamflow forecasters to consider stage forecast error in terms of actual values depicted in terms of median $\left(\Delta h_{\text {median }}\right)$, i.e.,

$$
\Delta h_{\text {median }}=\operatorname{median}\left(h_{s}-h_{o}\right) .
$$




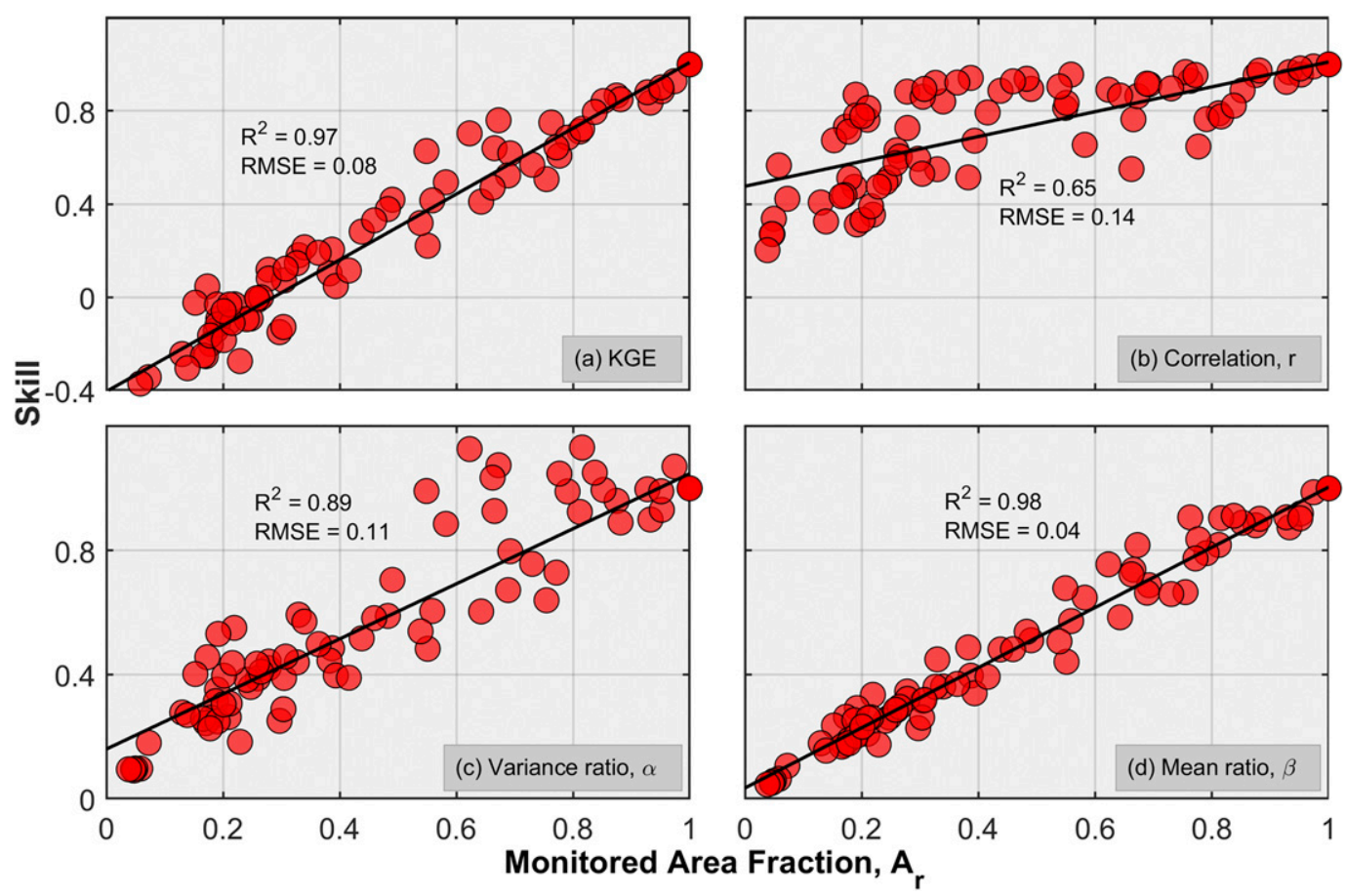

FIG. 8. Relationships of KGE metric decomposition components with monitored area fraction $A_{r}$ for pooled data from all basins in Iowa for the year 2016. (a) KGE shows strong linear dependence with $A_{r}$. The (b) correlation coefficient, (c) variance ratio, and (d) mean ratio show decreasing degree of dependence on $A_{r}$.

The normalized MAE ( $n \mathrm{MAE})$ for streamflow forecasts is computed similar to (7) but normalized by upstream drainage area. Hydrograph timing $T_{H}$ is associated with the cross correlation between the entire observed and forecast time series. We computed it as the number of hours a forecast time series needs to be shifted so that the cross-correlation coefficient is maximized. A positive value indicates delay in the timing of hydrograph while a negative value indicates early timing of forecast relative to the observed hydrograph. Timing of the peak $T_{P}$ is simply the difference in time at which the peak of forecast occurs relative to the peak of observations.

Next, we computed PPD as

$$
\mathrm{PPD}=\frac{\text { peak }_{\text {sim }}-\text { peak }_{\text {obs }}}{\text { peak }_{\text {obs }}} \times 100
$$

where peak $\mathrm{sim}_{\text {sim }}$ and peak $\mathrm{obs}_{\text {are }}$ the peaks of forecasts and observation respectively. We limit the consideration only to annual peaks (based on the observations).

\section{Results}

\section{a. Purely temporal persistence forecasts (PSPF)}

While Ghimire and Krajewski (2020) provide a comprehensive characterization of three persistence schemes, here we present their key result as it will be useful for our discussion of the spatiotemporal persistence. In Fig. 3, we show the KGE statistic for different forecast lead times up to three days ahead organized as a function of basin drainage area. It is interesting to note that for one-day-ahead forecast for basins of the size of about $1000 \mathrm{~km}^{2}$, this simple persistence method skill is about 0.8 , equivalent to a very good model (for a discussion of what is very good, see the analysis in Knoben et al. (2019). As Ghimire and Krajewski (2020) show, this skill can be even somewhat increased by incorporating simple climatology information.

\section{b. PSPF: Downstream direction}

In this scenario, the point of interest, e.g., a community, is downstream from the forecast point. In this study, we assume we have a stream gauge at the forecast location and can use the data to evaluate the quality of the forecast that used data from a point upstream. For example, consider the Cedar River basin and take streamflow data at Waverly, Iowa (gauge 2 in Fig. 6), and use them as the forecast for Cedar Rapids (gauge 5 in Fig. 6). The performance is not very good: the KGE is -0.1 with components of correlation of 0.49 , the mean ratio of 0.25 , and the variance ratio of 0.38 . However, if we now use data at Waterloo, Iowa (gauge 3 in Fig. 6), and use them to make forecasts for Cedar Rapids, 


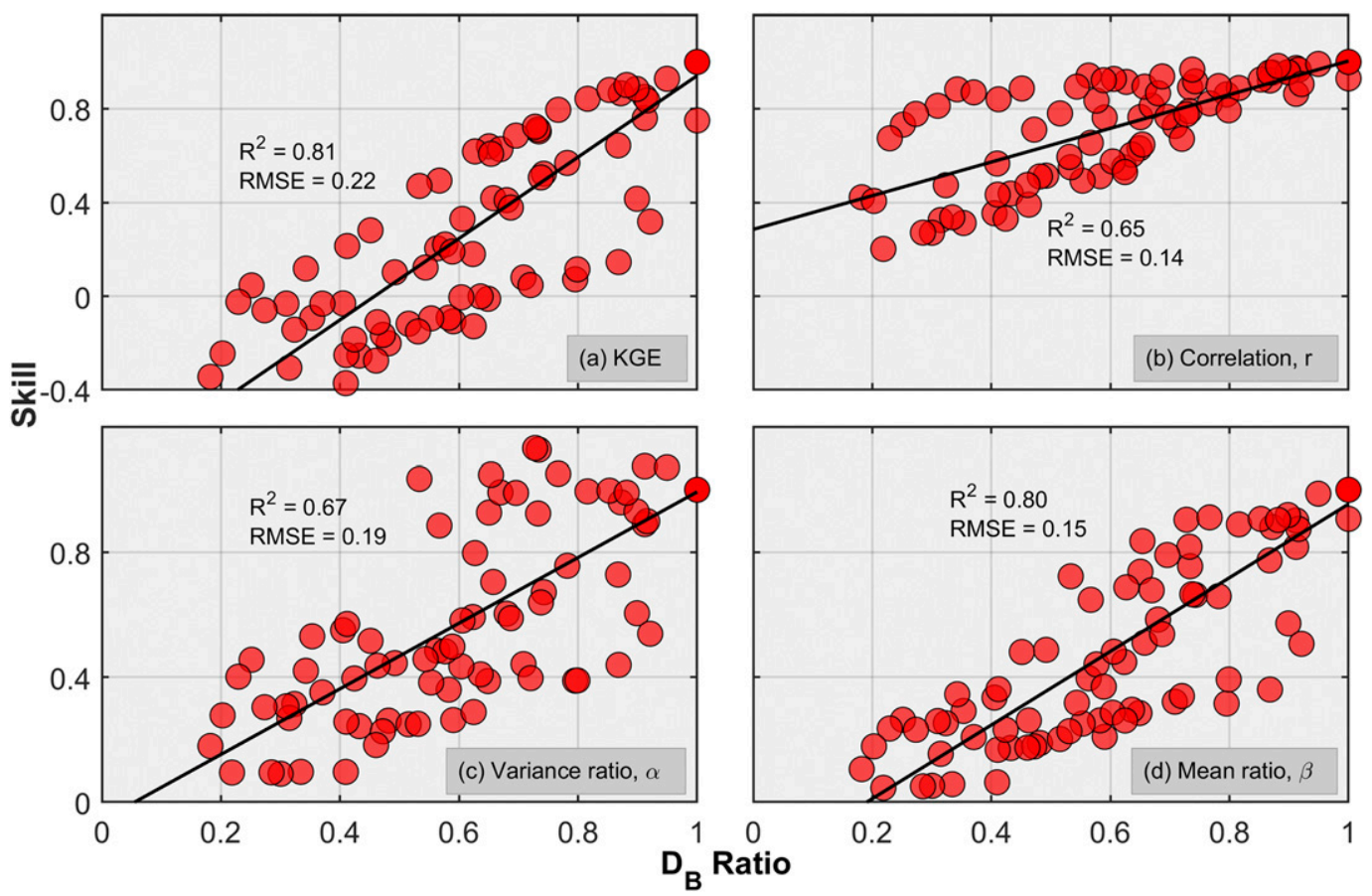

FIG. 9. Relationships of KGE metric decomposition components with base of the width function, $D_{B}$ ratio, for pooled data from all basins in Iowa for the year 2016. The dependence of KGE and its components with $D_{B}$ ratio is not as strong as with $A_{r}$ (see Fig. 8). Note that the correlation is explained similarly by both $D_{B}$ ratio and $A_{r}$.

the skill increases dramatically: the KGE goes up to 0.7. Now, we summarize the performance results for all possible combinations of the single point forecasts (SPFs) in Fig. 6 (see red dots) organizing them as function of the upstream drainage area ratio, hereafter referred to as monitored area fraction $A_{r}$ (e.g., gauge at Waterloo monitors drainage of about 0.8 of the basin area at Cedar Rapids). It is evident that using data from stations that capture over $70 \%$ of the basin of interest, i.e., $A_{r}=0.7$, persistence-based forecasting performs very well $(\mathrm{KGE}>0.5)$. The results shown here for the Cedar River basin, indicate strong relationship of the KGE measure and the monitored area fraction.

The performance increases if we combine data coming from different upstream branches of the river network (MPFs). A simple demonstration of how MPFs contribute to performance increase is shown by blue dots in Fig. 6. Here, green dots with forecast issued from gauge 1 transforms to magenta dots upon addition of forecast from gauge 2. The benefit does not apply to all stations as there are many locations that have only one station upstream. However, it is interesting to note that the performance based on MPFs also follows the strong relationship with $A_{r}$.

The above results are based on data for 2016. A natural question arises whether the same performance stays in other years. To illustrate the year-to-year variability, we have explored data for the 17-yr period, 2002-18. In Fig. 7, we show violin plots depicting distribution of KGE over this period for eight major basins (refer to Fig. 1 and Table 1) in Iowa. It is clear that both the median KGE (red line) and overall distribution display the same signature as in Fig. 6. A linear-regressionbased predictive model with goodness-of-fit measures is presented in Table 1. Clearly, $R^{2}$ and RMSE measures corroborates the strong relationship of KGE with $A_{r}$. Note that the intercept, $\alpha$ and slope parameter, $\beta$ of the predictive models show very small variability across basins except the Des Moines River. We speculate that this difference could be attributed to the distinct hydrogeology of this basin much of which is in the Des Moines Lobe characterized with pothole connectivity augmented by an extensive tile drainage network.

In Fig. 8, we show relationship of KGE and its decomposition components with $A_{r}$ for the pooled data from all basins for the year 2016. As discussed above, KGE statistic is explained strongly by $A_{r}$. Among its components, both bias and variance ratio show similar signature with $A_{r}$ while correlation does not show as strong relationship. It is interesting to explore if river network geometry in terms of width function can explain the variability in KGE and its components. It is clear from Fig. 9 that a width function descriptor of $D_{B}$ ratio does not explain the variability of KGE and its 

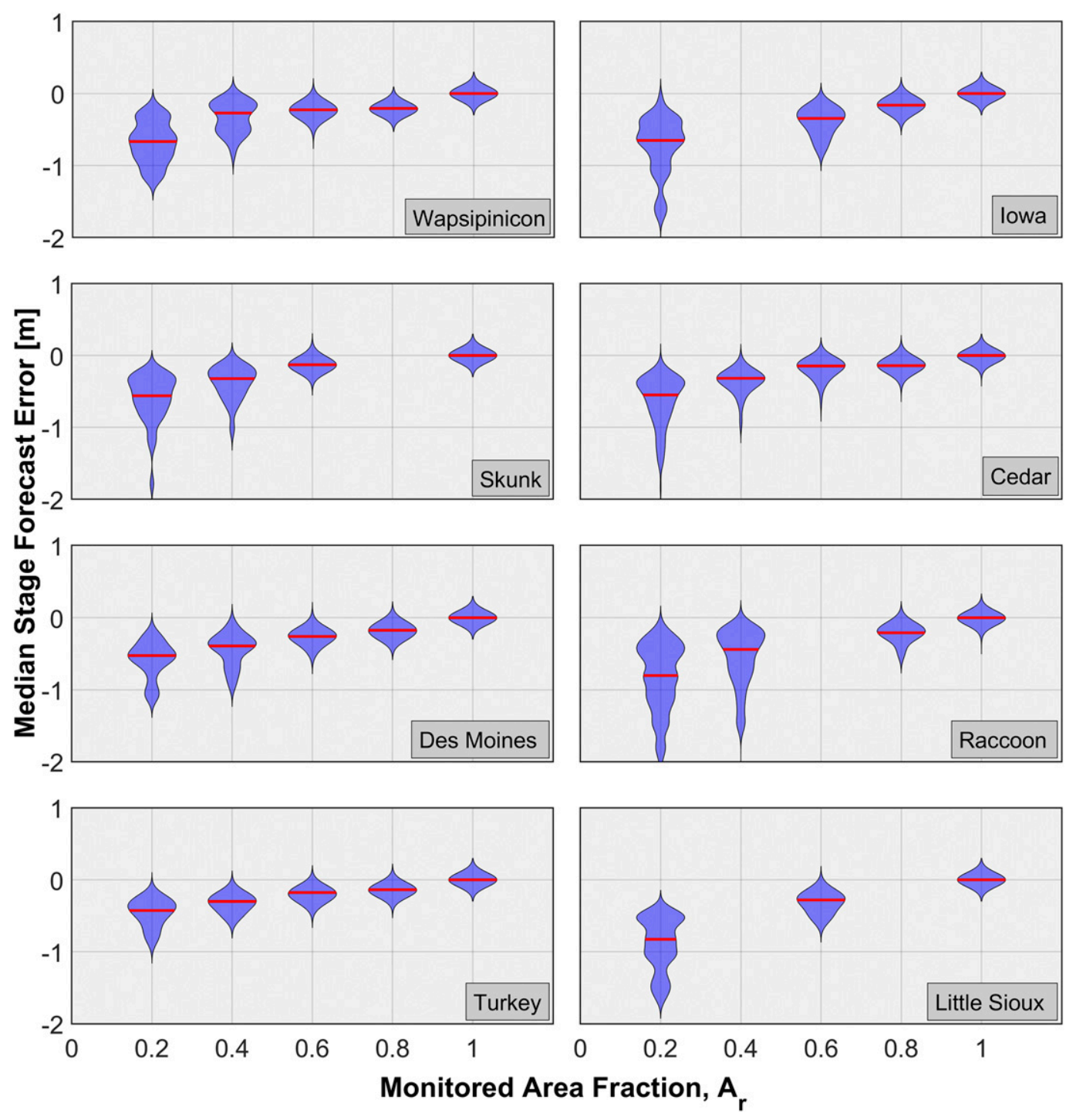

FIG. 10. Violin plots showing interannual variability of median stage forecast error with monitored area fraction $A_{r}$ across basins in Iowa. Each violin plot shows distribution of stage forecast error over the period of 2002-18. The red line shows the median of stage errors over the years.

components as strongly as $A_{r}$. However, note that correlation is explained almost equally well by the $D_{B}$ ratio. If this result is interpreted in conjunction with Fig. 5, larger variability in correlation with $A_{r}$ can also be explained by $D_{B}$ ratio. This, in turn, has implication for $T_{H}$ and $T_{P}$, which we discuss later.

While KGE may not be the ultimate performance criterion for the operational forecasters, its regular behavior with the monitored area fraction provides high level of confidence in the streamflow forecasting. However, for many applications, including flood forecasting, the variable of most interest is river stage. In Fig. 10, we evaluate our persistence forecasting in terms of stage errors. We use the rating curves provided by the
USGS to convert the computed discharge to stage. As the relationship between discharge and stage is influenced by the local hydraulic properties of the river channel, and because stage is measured with respect to an arbitrary datum, we expressed the results in terms of stage error in units of length (meters). In Fig. 10, we show the distribution of median of the stage errors obtained over a period of 17 years across eight basins in Iowa. The year-to-year variability is high, in particular, for cases of small $A_{r}$. Somewhat surprisingly, the median stage forecast errors are small for $A_{r}$ larger than 0.7. For $A_{r}>0.7$, median stage forecast errors are within $30 \mathrm{~cm}$ $(1 \mathrm{ft})$ for all basins indicating the potential of PSPF, which model-based forecasts should improve upon. 

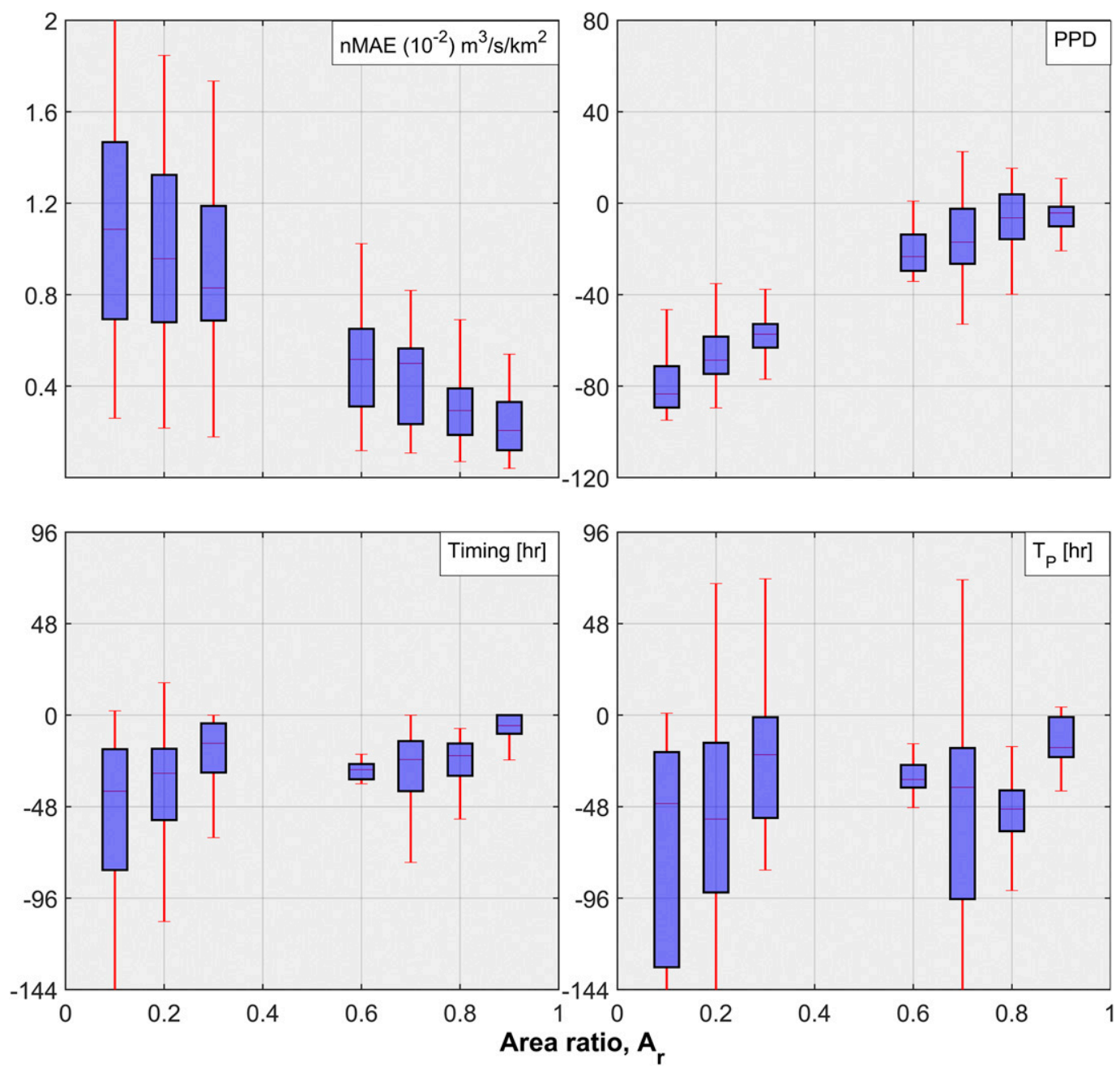

FIG. 11. Boxplots showing interannual variability of forecast skill measures normalized MAE (nMAE), percent peak difference (PPD), hydrograph timing $\left(T_{H}\right)$, and timing of the peaks $\left(T_{P}\right)$ with monitored area fraction $A_{r}$ for the Cedar River basin. The nMAE and PPD show strong dependence on $A_{r}$ while the signature of $T_{H}$ and $T_{P}$ with $A_{r}$ is not as strong.

In addition to the skill measures discussed above, operational forecasters are interested in other statistics while making streamflow forecasting decisions. In Fig. 11, we show variability of nMAE, PPD, $T_{H}$, and $T_{P}$ over the 17 -yr period with $A_{r}$ for the Cedar River basin. The variability and median values of nMAE and PPD show similar signature as KGE with $A_{r}$. These relationships of $T_{H}$ and $T_{P}$ with $A_{r}$ are similar but weaker. This weaker relationship is partly explained by the variability of correlation explained by the $D_{B}$ ratio (also see Fig. 9).

\section{c. PSPF: Upstream direction}

In this scenario, the point of interest, e.g., a community or a water intake or a wastewater discharge, is upstream from the forecast point. The results are similar but, surprisingly, worse than in the downstream direction, at least in terms of the KGE statistic (Fig. 12). This lack of symmetry between the downstream and upstream direction can be easily explained by the construction of the KGE metric. While the correlation coefficient between the predicted and observed series is immune to the upstream/downstream translation, the other terms of the KGE are ratios [see Eq. (5)]. In the downstream direction the predicted values are systematically lower than the observed (by construction of the forecasting scheme), therefore the mean ratio is always less than one. For the upstream direction, the ratio has the inverse value. The variance ratio behaves similarly. As a result, the KGE values are generally lower for the upstream case and not better relative to the mean of the observations (i.e., KGE $<-0.41$ ), especially for the $A_{r}$ 


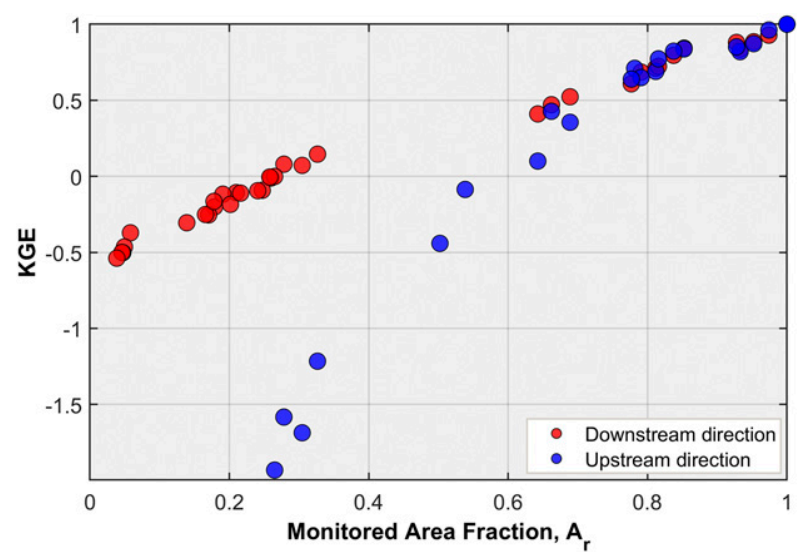

FIG. 12. Effect of forecast direction in the river network on the relationship between $\mathrm{KGE}$ and $A_{r}$. With upstream direction of persistence forecast, the persistence forecasts lose skill faster with $A_{r}$.

below 0.5. Note that in Fig. 12 we kept the ratio constrained by the larger-scale gauge, although this is inconsistent with its original definition (forecasted versus monitored area).

\section{d. Spatiotemporal persistence forecasts}

Here, we consider forecasting scenarios with lead time $\Delta t>0$, adding to the purely spatial persistence forecasts (PSPF) [see Eqs. (2) and (3)]. In the same framework discussed in section $4 \mathrm{c}$, we investigate the two-dimensional variability of performance metrics, i.e., with monitored area fraction $A_{r}$ and the lead time $\Delta t$. In Fig. 13, we show contour plots depicting the spatiotemporal persistence forecast skill in terms of nonparametric KGE for the Cedar River basin. Since these contour plots are empirically produced based on a limited sample size, lack of smoothness of the contours is expected. As a demonstration, we show here three basin scales in top to bottom panels (Figs. 13a-c) which represent the SPF points used to issue forecast at locations downstream. For example, consider the top panel. The data point is number 6 (see the reference map in the lower panel) and the forecast (evaluation) points are all other points located downstream, i.e., 7, 9, 11, 12,13 , and 14. Since the drainage area upstream of point 6 is $800 \mathrm{~km}^{2}$, and point 14 downstream drains $20000 \mathrm{~km}^{2}$, this evaluation set gives us a wide range of $A_{r}$. Interpolating and smoothing the contours gives a surface of $\mathrm{KGE}_{\mathrm{NP}}$. Similarly, for the data point 3 (Fig. 13b), with a somewhat smaller range of $A_{r}$. It is interesting to note that, for all scales at $\Delta t=3$ days and $A_{r}=0.6, \mathrm{KGE}_{\mathrm{NP}}$ is larger than 0.5.

Following from our discussion in section $4 \mathrm{c}$, one can fit regression models with $A_{r}$ and $\Delta t$ as explanatory variables giving rise to a contour plot that works for all
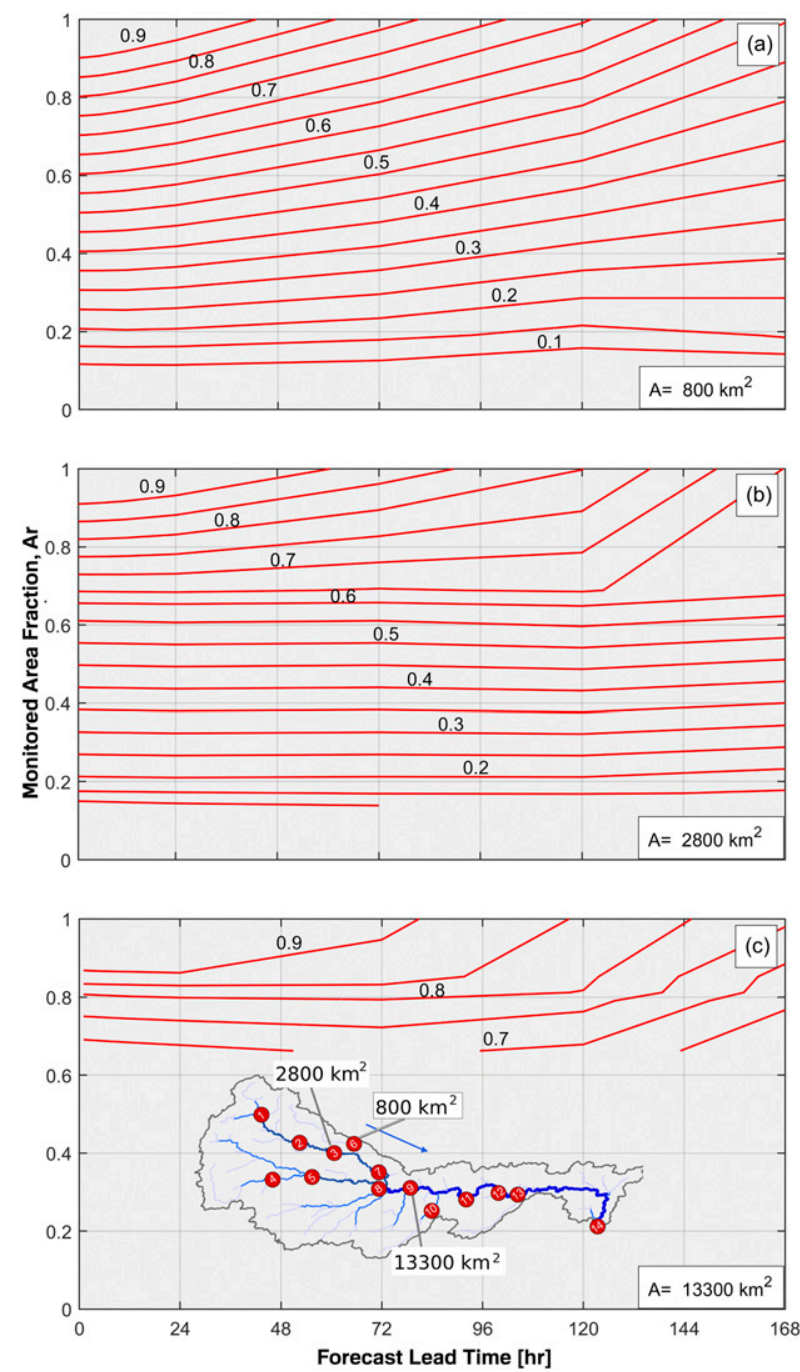

FIG. 13. Contour plots depicting the spatiotemporal persistence forecast skill in terms of nonparametric KGE (see contour labels) for the Cedar River basin. (a)-(c) Three basin scales represent the SPF points used to issue forecast at locations downstream. For example, for all scales at lead time of 3 days and $A_{r}$ of $0.6, \mathrm{KGE}_{\mathrm{NP}}$ is larger than 0.5 .

basin scales and can be used by forecasters for model evaluation. We have developed similar results (not shown) in terms of the KGE statistic.

\section{e. Adding velocity effect}

Staying true to the principle of extreme simplicity of this investigation, we would like to explore the effect of downstream water transport to improve the forecasting skill. Intuitively, it seems reasonable to expect that since water flows downstream, we should be able to improve the forecasting by applying the proper time offset. Since the distance along the river is known, the other piece of information we need is the water flow 


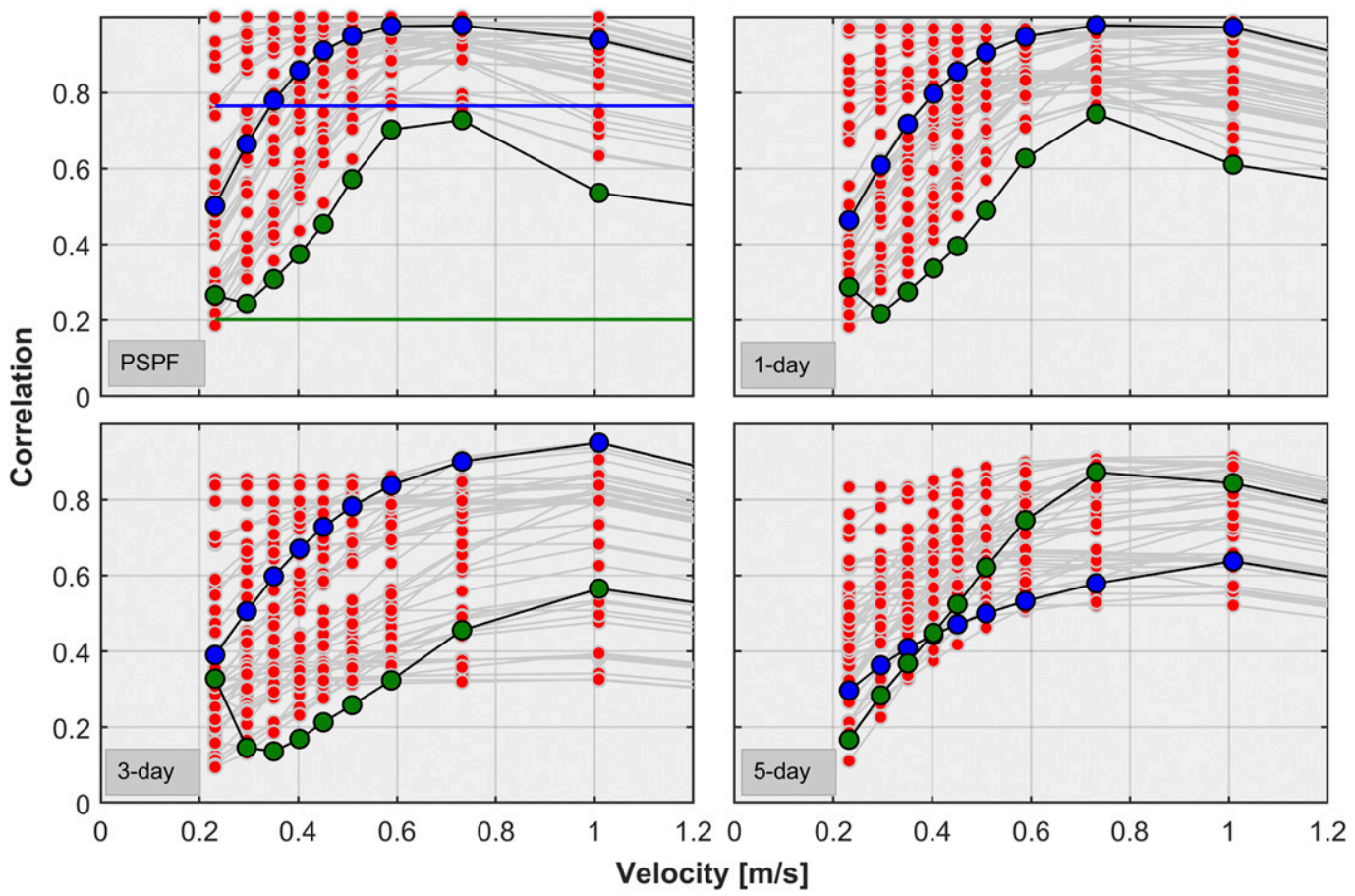

FIG. 14. Effect of constant velocity routing on pure SPF forecasts skill for the Cedar River basin. The panels show effect of constant velocity on correlation component of KGE across different lead times. The velocity axis shows the constant velocity used for routing PSPF forecasts while vertical axis shows correlation conditional on a given constant velocity. Each gray line connecting the red dots represents a value of $A_{r}$. Green and blue horizontal lines show the corresponding PSPF forecast skills (without routing velocity) for smaller $\left(A_{r}=0.04\right)$ and larger $\left(A_{r}=0.80\right)$ area ratios, respectively. The green and blue dotted lines show forecast skills for respective area ratios with the addition of constant routing velocity.

velocity. Assuming a constant velocity, the question becomes what value should we use? To address this question, we explored the empirical distribution of streamflow velocity based on USGS gauges in Iowa. We investigated over 100000 data points for the velocity distribution. The observed velocity in Iowa's streams and rivers ranges from 0.2 to over $2 \mathrm{~m} \mathrm{~s}^{-1}$. We investigated the velocities that correspond to each 10 th quantile of the distribution. It turns out that the best choice, in terms of maximizing the $\mathrm{KGE}$, is a velocity significantly higher than the median or the mean but not the very highest velocity.

In Fig. 14, we show the dependence of the correlation component of the KGE on the chosen constant velocity (each 10th quantile of the distribution) across different lead times for the Cedar River basin. From Figs. 8 and 9, it is evident that correlation is the least explained component of the KGE associated with the PSPF. The KGE metric itself shows little sensitivity with respect to velocity because it is dominated by mean and variance ratios. These two components show no sensitivity to the velocity as the same hydrographs are passed between the two gauges, just some faster and some slower. In the
Cedar River basin, we have a large number of USGS gauges, some added following the 2008 extreme flood (Smith et al. 2013). This results in many pairs of gauges and thus a wide range of the $A_{r}$. In Fig. 14, we show (in red dots) all possible SPF pairs. Those with small values of $A_{r}$ result in poor performance in terms of KGE. To facilitate the analysis, we selected two pairs: one with a small value of $A_{r}(\sim 0.04)$ shown in green, and second one with large (but not largest) $A_{r}(\sim 0.80)$ shown in blue. The corresponding color horizontal lines show the KGE for the PSPF. Recall that "purely spatial" refers to the case of $\Delta t=0$.

Several aspects of the problem become clear from the plots. Increasing the velocity for PSPF forecasts improves the correlation but only to a point. Further increase of the velocity will compromise the correlation. Also, the sensitivity is higher for the small $A_{r}$. The gauge pairs characterized by large $A_{r}$, show less impact of the velocity. This implies that the overall forecasting performance is dominated by the $A_{r}$. However, for some values of $A_{r}$, including velocity from the midrange of the observed values, improves the correlation and hence the overall forecasting performance. 
The addition of constant velocity to spatiotemporal persistence forecasts in section $4 \mathrm{~d}$ show similar dependency with $A_{r}$ and lead times. For both, large and small $A_{r}$, the effect of velocity is similar up to lead time of 3 days in addition to a systematic decrease in the correlation with lead times. Note that the correlation and overall forecasting performance is still superior up to 3 days. However, a notable difference emerges for the lead time of 5 days. The resulting correlation for small $A_{r}$ is higher than the correlation for large $A_{r}$ for midrange velocities. Because the travel time for the Cedar River basin is in the order of 5 days, the streamflow from small $A_{r}(\sim 0.04)$ will be in phase while the streamflow from large $A_{r}(\sim 0.80)$ will be out of phase. It has direct implication on $T_{H}$ and $T_{P}$ of the forecasts at the evaluation point. The result from Fig. 14 suggests that adding velocity to the spatiotemporal persistence forecasts has a particular implication to improving performance at longer lead times for small $A_{r}$. The effect of constant velocity on other statistics, such as nMAE, and PPD, results directly from the above results.

\section{f. Closing comments}

We hope that readers find the results of this simply constructed study interesting and useful. We demonstrate that data-only-based streamflow forecasting, if used in real time, has a high level of skill for wellinstrumented basins. Our results could be useful in several ways. We establish a performance reference level that more elaborate approaches, such as distributed hydrologic or AI based models should be expected to improve on. This reference is location dependent based on the configuration of the stream gauges. One simple demonstration of this is in Fig. 15. Here, we show the KGE along the river network in the Cedar River basin obtained by using the linear relationship from Fig. 6. The skill changes as the distance from the gauges increases (as the monitored area fraction changes as well). For each segment of the river network (or a link in the HLM nomenclature), we find the maximum skill for upstream or downstream (SPF or MPF) options. Adding IFC sensors would expand the useful skill of the persistence (assuming "perfect" rating curves).

The above results could serve as a basis for streamflow gauging network design as they clearly guide placing additional stream gauges to increase the $A_{r}$. They can also help with the assessment of the quality of synthetic rating curves developed for stage-only gauges (Kruger et al. 2016).

We foresee several extensions of this work in the direction of systematic assessment of the forecasting skill of hydraulic and hydrologic models. For example, we have demonstrated that it is difficult to find a constant
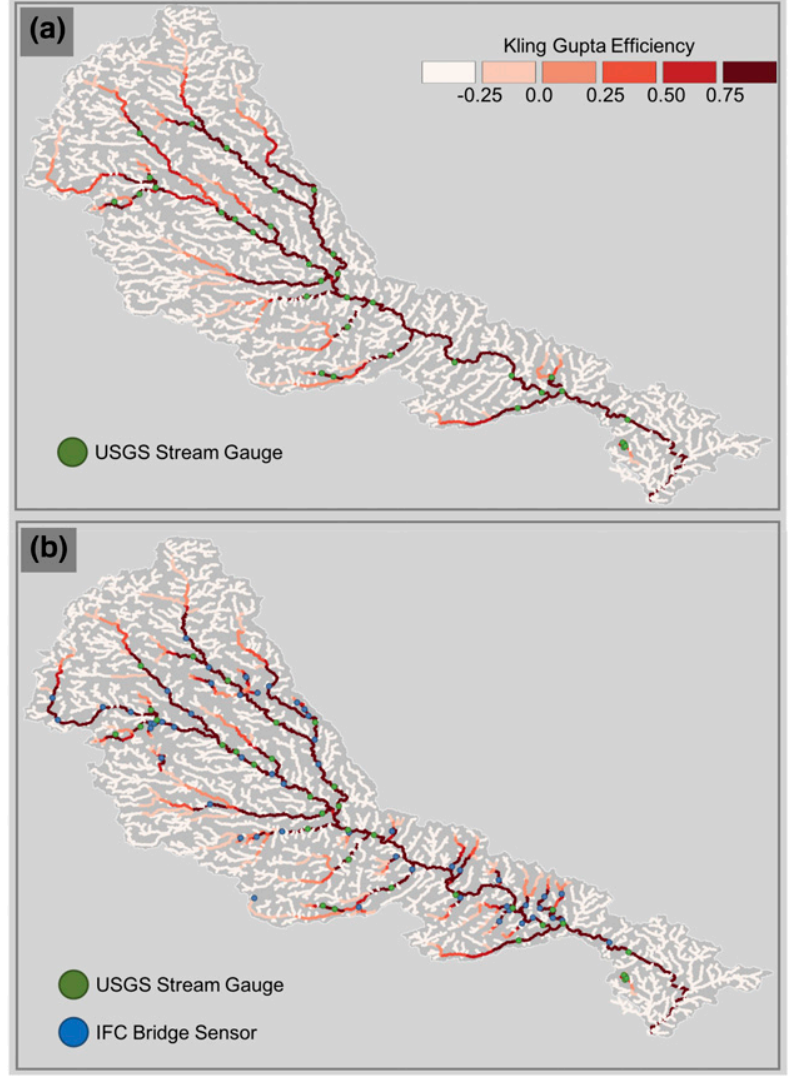

FIG. 15. Demonstration of pure SPF skill in terms of KGE in the river network using (a) the USGS only and (b) USGS and IFC bridge sensors as forecasting locations for each link. Addition of IFC bridge sensor in the network shows the potential for enhanced coverage of forecasts and improved the corresponding skill in the river network. The plot assumes perfect rating curves for both USGS and IFC gauge location.

velocity that improves upon a purely spatial approach. Would hydraulic models of open channel flow lead to better results? They require additional information in the form of channel geometric and hydraulic (roughness) properties. While the cross sections and slopes are straightforward to obtain, parametric description of roughness is subject to considerable uncertainty.

Finally, while comparing the spatiotemporal persistence forecasts skill to that of highly distributed (physically based) hydrologic models is outside the scope of this paper, we include an example in Fig. 16. It shows the KGE of an open-loop HLM model as well as the same model with a simple streamflow data assimilation scheme. The scheme is a replacement of the initial (boundary) conditions (the HLM is a system of ordinary differential equations) and thus directly comparable to the spatiotemporal persistence forecasts. The scheme does not modify system states or parameters upstream of the streamflow gauge. The results show 

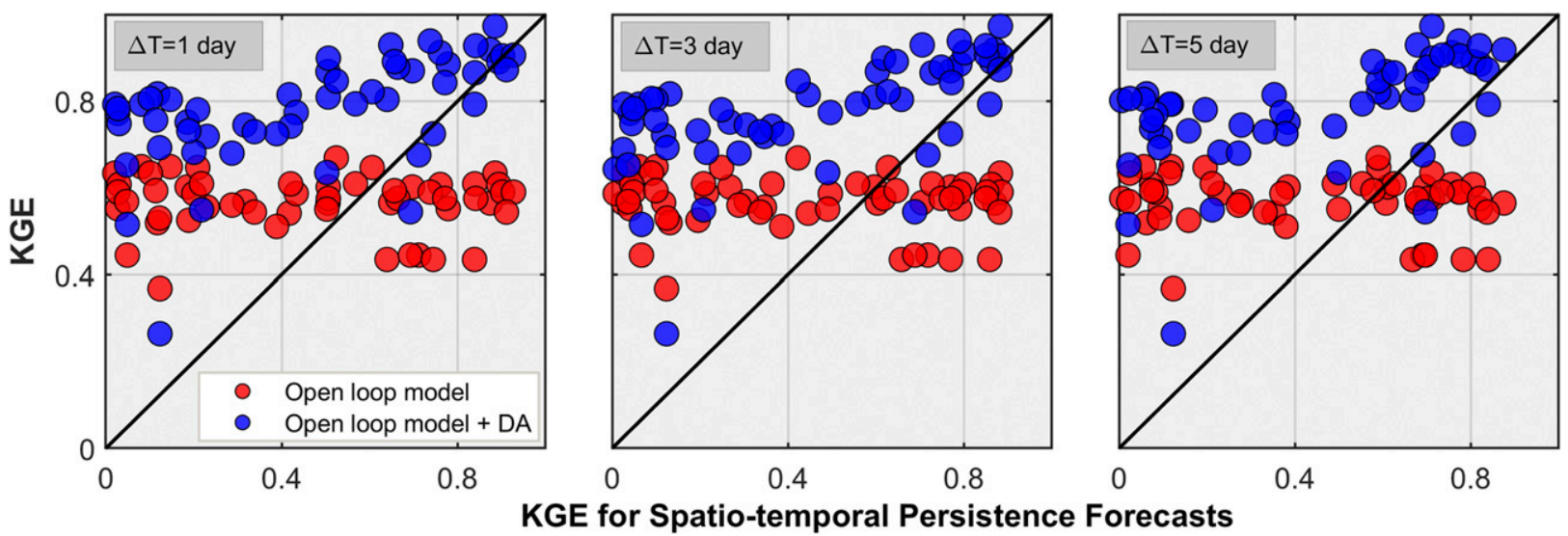

FIG. 16. One-to-one comparison of a hydrologic model forecast skill with the spatiotemporal persistence forecasts skill. Both axes show the positive range of the KGE values. Red dots show the comparison of KGE of the open-loop HLM model with spatiotemporal persistence forecasts while blue dots show the comparison of KGE of simple data assimilated open-loop model with spatiotemporal persistence forecasts. This scatterplot shows a potential of enhanced forecast skill upon adding modeling complexity to spatiotemporal persistence forecasts.

better forecast skill of the HLM in terms of KGE for basins with smaller $A_{r}$ and for longer lead times. For example, from lead time of 1 day to 5 days the forecast skill of the HLM model starts bettering the performance of spatiotemporal persistence forecasts at more locations. Note the shift of more stations to the left of the diagonal with the increase of lead times. With the addition of the simple data assimilation framework, the HLM forecast skill is enhanced over spatiotemporal persistence forecasts, as expected. The HLM simulation shown in Fig. 16 assumes "perfect" rainfall forecast (i.e., limited only to the observational and estimation errors). In reality, the rainfall forecasts are subject to considerable uncertainty, especially for the longer lead times (e.g., Seo et al. 2018).

Acknowledgments. This study was funded by the Iowa Flood Center of the University of Iowa. The first author also acknowledges partial support from the Rose and Joseph Summers endowment. The authors are grateful to many colleagues at the IFC who facilitated the study by providing observational and computational support. We thank two reviewers whose constructive and insightful comments led to an improved paper.

\section{REFERENCES}

Ayalew, T. B., and W. F. Krajewski, 2017: Effect of river network geometry on flood frequency: A tale of two watersheds in Iowa. J. Hydrol. Eng., 22, 1-7, https://doi.org/10.1061/(ASCE) HE.1943-5584.0001544.

, - - and R. Mantilla, 2014a: Connecting the power-law scaling structure of peak-discharges to spatially variable rainfall and catchment physical properties. Adv. Water Resour., 71, 32-43, https://doi.org/10.1016/j.advwatres.2014.05.009. ,$--\frac{-}{-}$, and S. J. Small, 2014b: Exploring the effects of hillslope-channel link dynamics and excess rainfall properties on the scaling structure of peak-discharge. Adv. Water Resour., 64, 9-20, https://doi.org/10.1016/j.advwatres.2013.11.010.

Betterle, A., M. Schirmer, and G. Botter, 2017: Characterizing the spatial correlation of daily streamflows. Water Resour. Res., 53, 1646-1663, https://doi.org/10.1002/2016WR019195.

Botter, G., S. Zanardo, A. Porporato, I. Rodriguez-Iturbe, and A. Rinaldo, 2008: Ecohydrological model of flow duration curves and annual minima. Water Resour. Res., 44, 1-12, https://doi.org/10.1029/2008WR006814.

Castiglioni, S., A. Castellarin, A. Montanari, J. O. Skøien, G. Laaha, and G. Blöschl, 2011: Smooth regional estimation of low-flow indices: Physiographical space based interpolation and topkriging. Hydrol. Earth Syst. Sci., 15, 715-727, https://doi.org/ 10.5194/hess-15-715-2011.

Cunha, L. K., P. V. Mandapaka, W. F. Krajewski, R. Mantilla, and A. A. Bradley, 2012: Impact of radar-rainfall error structure on estimated flood magnitude across scales: An investigation based on a parsimonious distributed hydrological model. Water Resour. Res., 48, 1-22, https://doi.org/10.1029/2012WR012138.

Demir, I., and W. F. Krajewski, 2013: Towards an integrated Flood Information System: Centralized data access, analysis, and visualization. Environ. Modell. Software, 50, 77-84, https:// doi.org/10.1016/j.envsoft.2013.08.009.

Doulatyari, B., A. Betterle, S. Basso, B. Biswal, M. Schirmer, and G. Botter, 2015: Predicting streamflow distributions and flow duration curves from landscape and climate. Adv. Water Resour., 83, 285-298, https://doi.org/10.1016/j.advwatres.2015.06.013.

Dralle, D. N., N. J. Karst, and S. E. Thompson, 2016: Dry season streamflow persistence in seasonal climates. Water Resour. Res., 52, 90-107, https://doi.org/10.1002/2015WR017752.

ElSaadani, M., W. F. Krajewski, R. Goska, and M. B. Smith, 2018: An investigation of errors in distributed models' stream discharge prediction due to channel routing. J. Amer. Water Resour. Assoc., 54, 742-751, https://doi.org/10.1111/ 1752-1688.12627.

Ghimire, G. R., and W. F. Krajewski, 2020: Exploring persistence in streamflow forecasting. J. Amer. Water Resour. Assoc., 56, 542-550, https://doi.org/10.1111/1752-1688.12821. 
- - — , and R. Mantilla, 2018: A power law model for river flow velocity in Iowa basins. J. Amer. Water Resour. Assoc., 54, 1055-1067, https://doi.org/10.1111/1752-1688.12665.

Gupta, H. V., H. Kling, K. K. Yilmaz, and G. F. Martinez, 2009: Decomposition of the mean squared error and NSE performance criteria: Implications for improving hydrological modelling. J. Hydrol., 377, 80-91, https://doi.org/10.1016/ j.jhydrol.2009.08.003.

Knoben, W. J. M., J. E. Freer, and R. A. Woods, 2019: Technical note: Inherent benchmark or not? Comparing Nash-Sutcliffe and Kling-Gupta efficiency scores. Hydrol. Earth Syst. Sci., 23, 4323-4331, https://doi.org/10.5194/HESS-23-4323-2019.

Krajewski, W. F., and Coauthors, 2017: Real-time flood forecasting and information system for the State of Iowa. Bull. Amer. Meteor. Soc., 98, 539-554, https://doi.org/10.1175/BAMS-D-15-00243.1.

Kruger, A., W. F. Krajewski, J. J. Niemeier, D. L. Ceynar, and R. Goska, 2016: Bridge-Mounted River Stage Sensors (BMRSS). IEEE Access, 4, 8948-8966, https://doi.org/ 10.1109/ACCESS.2016.2631172.

Laaha, G., J. O. Skøien, and G. Blöschl, 2014: Spatial prediction on river networks: Comparison of top-kriging with regional regression. Hydrol. Processes, 28, 315-324, https://doi.org/ 10.1002/hyp.9578.

Mallakpour, I., and G. Villarini, 2015: The changing nature of flooding across the central United States. Nat. Climate Change, 5, 250-254, https://doi.org/10.1038/nclimate2516.

Mantilla, R., 2007: Physical basis of statistical scaling in peak flows and stream flow hydrographs for topologic and spatially embedded random self-similar channel networks. Ph.D. thesis, University of Colorado, Boulder, $144 \mathrm{pp}$.

- , and V. K. Gupta, 2005: A GIS numerical framework to study the process basis of scaling statistics in river networks. IEEE Geosci. Remote Sens. Lett., 2, 404-408, https://doi.org/10.1109/ LGRS.2005.853571.

Müller, M. F., and S. E. Thompson, 2016: Comparing statistical and process-based flow duration curve models in ungauged basins and changing rain regimes. Hydrol. Earth Syst. Sci., 20, 669-683, https://doi.org/10.5194/hess-20-669-2016.

_ D. N. Dralle, and S. E. Thompson, 2014: Analytical model for flow duration curves in seasonally dry climates. Water Resour. Res., 50, 5510-5531, https://doi.org/10.1002/2014WR015301.

Palash, W., Y. Jiang, A. S. Akanda, D. L. Small, A. Nozari, and S. Islam, 2018: A streamflow and water level forecasting model for the Ganges, Brahmaputra, and Meghna Rivers with requisite simplicity. J. Hydrometeor., 19, 201-225, https://doi.org/ 10.1175/JHM-D-16-0202.1.

Perez, G., R. Mantilla, and W. F. Krajewski, 2018: The influence of spatial variability of width functions on regional peak flow regressions. Water Resour. Res., 54, 7651-7669, https://doi.org/ 10.1029/2018WR023509.

Pool, S., M. Vis, and J. Seibert, 2018: Evaluating model performance: Towards a non-parametric variant of the Kling-Gupta efficiency. Hydrol. Sci. J., 63, 1941-1953, https://doi.org/ 10.1080/02626667.2018.1552002.

Prior, J. C., 1991: Landforms of Iowa. University of Iowa Press, $168 \mathrm{pp}$.
Quintero, F., W. F. Krajewski, R. Mantilla, S. Small, and B.-C. Seo, 2016: A spatial-dynamical framework for evaluation of satellite rainfall products for flood prediction. J. Hydrometeor., 17, 2137-2154, https://doi.org/10.1175/JHM-D-15-0195.1.

_ , R. Mantilla, C. Anderson, D. Claman, and W. Krajewski, 2018: Assessment of changes in flood frequency due to the effects of climate change: Implications for engineering design. Hydrology, 5, 19, https://doi.org/10.3390/hydrology5010019.

— - W. F. Krajewski, B.-C. Seo, and R. Mantilla, 2020: Improvement and evaluation of the Iowa Flood Center Hillslope Link Model (HLM) by calibration-free approach. J. Hydrol., 548, 124686, https://doi.org/10.1016/j.jhydrol.2020.124686.

Rodriguez-Iturbe, I., and A. Rinaldo, 1997: Fractal River Basins: Chance and Self-Organization. Cambridge University Press, $565 \mathrm{pp}$.

Schilling, K. E., C. F. Wolter, and E. McLellan, 2015: Agrohydrologic landscapes in the upper Mississippi and Ohio River Basins. Environ. Manage., 55, 646-656, https://doi.org/ 10.1007/s00267-014-0420-x.

- , P. W. Gassman, A. Arenas-Amado, C. S. Jones, and J. Arnold, 2019: Quantifying the contribution of tile drainage to basin-scale water yield using analytical and numerical models. Sci. Total Environ., 657, 297-309, https://doi.org/ 10.1016/j.scitotenv.2018.11.340.

Seo, B. C., and Coauthors, 2018: Comprehensive evaluation of the IFloodS radar rainfall products for hydrologic applications. J. Hydrometeor., 19, 1793-1813, https://doi.org/ 10.1175/JHM-D-18-0080.1.

Skøien, J. O., R. Merz, and G. Blöschl, 2006: Top-kriging - Geostatistics on stream networks. Hydrol. Earth Syst. Sci., 10, 277-287, https://doi.org/10.5194/hess-10-277-2006.

Small, S. J., L. O. Jay, R. Mantilla, R. Curtu, L. K. Cunha, M. Fonley, and W. F. Krajewski, 2013: An asynchronous solver for systems of ODEs linked by a directed tree structure. Adv. Water Resour., 53, 23-32, https://doi.org/10.1016/ j.advwatres.2012.10.011.

Smith, J. A., M. L. Baeck, G. Villarini, D. B. Wright, and W. Krajewski, 2013: Extreme flood response: The June 2008 flooding in Iowa. J. Hydrometeor., 14, 1810-1825, https:// doi.org/10.1175/JHM-D-12-0191.1.

Villarini, G., J. A. Smith, M. L. Baeck, and W. F. Krajewski, 2011a: Examining flood frequency distributions in the midwest U.S. J. Amer. Water Resour. Assoc., 47, 447-463, https://doi.org/ 10.1111/j.1752-1688.2011.00540.x.

,,,--- R. Vitolo, D. B. Stephenson, and W. F. Krajewski, 2011b: On the frequency of heavy rainfall for the Midwest of the United States. J. Hydrol., 400, 103-120, https://doi.org/ 10.1016/j.jhydrol.2011.01.027.

,$- \ldots$, and G. A. Vecchi, 2013: Changing frequency of heavy rainfall over the central United States. J. Climate, 26, 351-357, https://doi.org/10.1175/JCLI-D-12-00043.1.

Zalenski, G., W. F. Krajewski, F. Quintero, P. Restrepo, and S. Buan, 2017: Analysis of national weather service stage forecast errors. Wea. Forecasting, 32, 1441-1465, https:// doi.org/10.1175/WAF-D-16-0219.1. 